\title{
Evaluation of the Acute and Sub-chronic Toxic Effects of Aqueous Leaf Extracts of Artemisia afra on Liver, Kidney and Some Blood Parameters in Wistar Rats
}

\author{
Nikodimos Eshetu ${ }^{1, *}$, Mekbeb Afework ${ }^{2}$, Eyasu Makonnen $^{3}$, Asfaw Debella ${ }^{4}$, Wondwossen Ergete ${ }^{5}$, \\ Tesfaye Tolesssa ${ }^{6}$ \\ ${ }^{1}$ Department of Biomedical, College of Health Sciences, Mizan Tepi University, Mizan Teferi, Ethiopia \\ ${ }^{2}$ Department of Anatomy, College of Health Sciences, Addis Ababa University, Addis Ababa, Ethiopia \\ ${ }^{3}$ Department of Pharmacology, College of Health Sciences, Addis Ababa University, Addis Ababa, Ethiopia \\ ${ }^{4}$ Ethiopian Public Health Institute, Addis Ababa, Ethiopia \\ ${ }^{5}$ Department of Pathology, College of Health Sciences, Addis Ababa University, Addis Ababa, Ethiopia \\ ${ }^{6}$ Department of physiology, College of Health Sciences, Addis Ababa University, Addis Ababa, Ethiopia
}

\section{Email address:}

nixon.eshetu@gmail.com (N. Eshetu), mekbebafework@yahoo.co.uk (M. Afework), eyasumakonnen@yahoo.com (E. Makonnen), asfawdebella@gmail.com (A. Debella),wondwossen_ergete@yahoo.com (W. Ergete), tesfayet2002@yahoo.com (T. Tolesssa)

${ }^{*}$ Corresponding author

\section{To cite this article:}

Nikodimos Eshetu, Mekbeb Afework, Eyasu Makonnen, Asfaw Debella, Wondwossen Ergete, Tesfaye Tolesssa. Evaluation of the Acute and Sub-chronic Toxic Effects of Aqueous Leaf Extracts of Artemisia afra on Liver, Kidney and Some Blood Parameters in Wistar Rats. Advances in Bioscience and Bioengineering. Vol. 1, No. 1, 2016, pp. 1-9. doi: 10.11648/j.abb.20160401.12

Received: May 27, 2016; Accepted: June 3, 2016; Published: June 17, 2016

\begin{abstract}
Background: Artemisia afra is a plant traditionally used for treatment of different diseases in many parts of the world including Ethiopia. Its effects on different organs, however, have not yet been investigated. The objective of the present study was, therefore, to evaluate the acute and sub-chronic toxic effects of aqueous leaf extracts of Artemisia afra on Liver, Kidney and some Blood parameters in Rats. Methods: For acute toxicity study, aqueous extracts of the leaves were administered in a single dose of $200,700,1200,2200,3200,4200$ and $5000 \mathrm{mg} / \mathrm{kg}$ body weight, while the low dose $(600 \mathrm{mg} / \mathrm{kg})$ and triple of lower dose $(1800 \mathrm{mg} / \mathrm{kg})$ were used for sub-chronic toxicity studies. Selected hematological and biochemical parameters of the blood followed by histopathological analysis were investigated after 90 days of daily administrations. The results were expressed as $\mathrm{M} \pm \mathrm{SE}$, and differences at $\mathrm{P}<0.05$ were considered significant. Differences between the experimental and control groups were analyzed using one-way analysis of variance (ANOVA), followed by Dunnett's T-test to determine their level of significance. Results: The current study showed that the median oral lethal dose (LD50) was greater than $5000 \mathrm{mg} / \mathrm{kg}$. Acute toxicity study revealed some changes in general behavior of the rats above $3200 \mathrm{mg} / \mathrm{kg}$. The levels of blood parameters did not change though AST level decreased significantly in female animals after 90 days of sub-chronic treatment with $1800 \mathrm{mg} / \mathrm{kg}$. Histopathological presentations were generally normal though there were mild mononuclear leukocytic infiltrations around the central venules \& portal areas of rats' liver at both 600 and $1800 \mathrm{mg} / \mathrm{kg}$ dose. Furthermore, minor tubulointerstitial leukocytic infiltrations were observed in small areas of kidney sections treated at higher dose. Conclusion: The aqueous extract of Artemisia afra at the test doses did not show significant toxicity: the minor inflammatory changes observed in this study were not accompanied by significant change in any of the hematological and biochemical markers of liver injury. It might be a response to parenchymal cell death with causes ranging from infectious agents, exposure to toxicants, generation of toxic metabolites, and tissue anoxia.
\end{abstract}

Keywords: Artemisia afra, Traditional Medicine, Toxicological Assessment 


\section{Introduction}

Use of plants as medicines is as old as human civilization [1]. The strong historical bond between plants and human health is well substantiated by plant species diversity and related knowledge of their use as herbal medicines [2].

More than 35,000 plant species are reported as being used across the globe for medicinal purposes [3]. In Africa, more than 2,000 plants have been identified and used as herbal medicines to treat several ailments, but very few of these plants have been screened for their safety [4]. The current account of medicinal plants of Ethiopia shows about 887 plant species are utilized as traditional medicine in Ethiopia. Among these, about 26 species are endemic [5]. In Western and African folk medicine, several species of the Genus, Artemisia are used for their claimed healing properties and the curing of specific ailments. Among those species Artemisia afra is one of the widely used medicinal plants [6].

Artemisia afra is a herb growing in the high land areas of Eastern and Southern Africa. In Ethiopia, it usually grows in rocky mountainous areas along forest margins and stream sides, and its natural distribution extends from Bale mountains National Park (Dinsho) southeastern to northern parts of Ethiopia [7]. It is also predominantly found in Asia, Europe and North America [8].

Artemisia afra is widely used in many parts of the world either alone or in combination with other plants as herbal remedies for a variety of ailments like simple headache to neurological disorder [9]. In South Africa, it is mainly employed as a remedy for chest conditions, coughs, colds, heart burns, hemorrhoids, fevers, malaria, asthma, and other conditions [10-13]. In Ethiopia, healers use the plant for Epilepsy (Dhibe Qabana), Evil eye (Buda) and febrile illness (Michi) The aqueous extract of $A$. afra showed bronchodilator activity [14], as well as anti-histaminic and analgesic properties [10]. The ethanolic and dichloromethane extracts of the plant have shown to have in vitro hypotensive and antituberculosis effects, respectively [15]. A. afra is also traditionally used in the treatment of malaria [16]. Despite its' multiple uses, very little is known about the toxicity of this plant [17], which is an issue this study is aimed to investigate.

\section{Methodology}

\subsection{Plant Materials}

The fresh leaves of $A$. afra were collected from Bale National mountain of Ethiopia based on its ethno-botanical description and the compliance of the Bale National park in July 2014. Specimens of the plant were identified by a taxonomist and samples were deposited at the National Herbarium with a Voucher specimen number (392/NKI/PHARM) at the college of natural and computational sciences, Addis Ababa University (AAU). Fresh leaves were cleaned from extraneous materials, dried under shade at room temperature, and grinded by manual crusher as described by Debella [18]

\subsection{Preparation of Aqueous Leaf Extract of Artemisia afra}

The powdered leaves (620gm Artemisia afra) were macerated with distilled water for $2-3$ hrs with intermittent agitation by orbital shaker. Then, the supernatant was decanted and filtered with $0.1 \mathrm{~mm}^{2}$ mesh gauze from the undissolved portion of plant. The filtrate was freeze-dried at lower temperature and reduced pressure to form crude extract. A yield of $67.7 \mathrm{gm}(10.9 \%)$ was obtained. This was kept in a desicator at room temperature until used.

\subsection{Experimental Animals}

The animals used in this study were bred and reared at the animal house of the Ethiopian Public Health Institute and transported to Physiology Laboratory of College of Health Science Addis Ababa University. Experiments were conducted on 59 healthy adult male and female Wistar rats aged 8-12 weeks for both acute and sub-chronic study. Thirty two female rats in 8 groups were used for acute study. The remaining 27 rats (12 male and 15 female) were used for subchronic study and grouped in six: three groups (for male) which contained four rats in each group and three groups (for females), each group contained five rats. Females were nulliparous and non-pregnant. Grouping of rats was done randomly. The animals were kept in separate aluminum cages and provided with bedding of clean paddy husk. All animals had free access to standard pellet diet and tap water ad libitum. The rats were acclimatized to laboratory conditions for one week prior to the experimental protocol to minimize any nonspecific stress [19]. They were maintained at standard temperature $\left(20 \pm 3^{\circ} \mathrm{C}\right)$ and alternative $12 \mathrm{hrs}$ light/dark cycles till the end of the experiment based on WHO Research guidelines for evaluating the safety and efficacy of herbal medicines [20]

Selection of the dose for acute toxicological investigation were based on the efficacy data on the plant by Taofik and Anthony [21] who reported $200 \mathrm{mg} / \mathrm{kg}$ body weight aqueous extract to be effective dose in decreasing serum glucose level. All groups of rats were fasted overnight prior to treatment. At the end of the fasting period, the body weight of each rat was recorded before dosing. Each treated group (groups 1 to 7 ) received designated doses $(200 \mathrm{mg} / \mathrm{kg}$ to $5000 \mathrm{mg} / \mathrm{kg}$ of the formulation per body weight) to see a range of toxic effects and mortality rates in 24 hours observation. The control group (Group 8) received distilled water in the same volume.

The subchronic toxicity study was carried out for 90 days. In this study, two doses (600 and $1800 \mathrm{mg} / \mathrm{kg}$ body weight) were selected. The low dose was based on the findings in acute toxicity study and tripled low dose $(1800 \mathrm{mg} / \mathrm{kg})$ was taken as the higher dose [22]. The main study sample of twenty seven rats (12 adult male and 15 female rats) weighing 130-270g were housed in groups of 6 in a rat cages, under the same conditions as described previously for the acute study. The body-weight (in gram) of each rat was 
recorded on the $1^{\text {st }}$ day and at weekly intervals throughout the course of the study and the average body-weights for the groups were calculated. Twenty-four hours after the last day of extract administration, each animal was anaesthetized by diethyl ether and put on dissecting board in supine position and blood samples were drawn by cardiac puncture. Blood samples obtained from each rat was then collected in separate test tubes with, EDTA (ethylene diamine tetra-acetic acid) and the remaining in plain test tubes with no EDTA. Blood samples from EDTA containing test tubes were immediately processed for hematological parameters using Automated Hematological Analyzer, (SYSMEX RX 21, Japan). For biochemical analysis, the blood samples in the plain test tubes were allowed to stand for 3 hours for complete clotting and then centrifuged at $5000 \mathrm{rpm}$ for 15 minutes using a bench top centrifuge (HUMAX-K, HUMAN-GmbH, Germany). The serum was drawn and transferred into other clean vials and kept at $-20^{\circ} \mathrm{C}$ until analysis for clinical chemistry measurements. After blood collection, each rat was sacrificed humanly, the whole liver and both right and left kidneys were immediately excised. The gross pathological observation of these organs was performed to check for any lesions. Eventually, all the samples were sliced and preserved in $10 \%$ neutral buffered formalin fixative solution for 24 hours.

\subsection{Tissue Processing}

The liver and the kidney tissue samples of the various groups of rats preserved in 10\% neutral buffered formalin were thoroughly rinsed over several changes of tap water. They were then dehydrated with increasing concentrations of ethanol (70\% and 90\%) for 2 hours each followed by absolute alcohol I, II, and III for one and half hours, each and absolute alcohol IV, overnight.

The tissue samples were cleared with two changes of xylene: xylene-I for one and half hours and xylene-II for two and half hours. Next, the tissues were impregnated in paraffin wax: wax-I for two and half hours and wax-II overnight in an oven at a temperature of $40^{\circ} \mathrm{C}$. Embedding the tissue samples into tissue block was done by putting tissue samples in squares of metal plates and carefully pouring molten paraffin over them. After proper orientation of the specimens all tissue blocks were labeled and allowed to harden at room temperature.

Tissue blocks were sectioned at a thickness of $5 \mu \mathrm{m}$ using Leica rotary microtome. Ribbons of the tissue sections were gently collected using a piece of camel brush and laid onto the surface of a water bath heated at $40^{\circ} \mathrm{C}$. After the sections were appropriately spread on the water bath, they were mounted on to tissue slides. The slides were arranged in slide racks and were placed in an oven with a temperature of $40^{\circ} \mathrm{C}$ overnight to facilitate the adhesion of the specimens onto the glass slides. The specimens were allowed to cool and stained using Heamatoxylin \& Eosin staining method and mounted with DPX.

\subsection{Ethical Consideration}

The study was conducted after having approval by Department of Anatomy Ethics Review Committee and School of Medicine, College of Health Sciences with Protocol number: 158/09/Anat., Addis Ababa University. Animals used in this study were protected from any unnecessary painful and terrifying situations [23].

\subsection{Statistical Analysis}

All data were organized and analyzed using SPSS version 21 statistical software. The values of body and organ weight changes and difference, hematological and biochemical parameters were analyzed and the results were expressed as $\mathrm{M} \pm \mathrm{SE}(\mathrm{x})$ (standard error of the mean). Differences between the experimental and control groups were compared using one-way analysis of variance (ANOVA), followed by Dunnett's T-test to determine their level of significance. Differences at $\mathrm{p}<0.05$ were considered statistically significant.

\section{Results}

\subsection{Acute Toxicity}

\subsubsection{Effects of Acute Administration of Extract on Behavior and Body Weight}

Aqueous leaf extract of Artemisia afra did not show any mortality with single oral doses up to $5000 \mathrm{mg} / \mathrm{kg}$ body weight. Behavioral changes like loss of appetite, hypoactivity, pilo-erection, lethargic, dizziness and a single episode of convulsion were observed at the dose of $3200 \mathrm{mg} / \mathrm{kg}$ and above, with an increased severity as the dose increased. The symptoms, however, disappeared after washout period of the first week of observation.

Both the treated and control groups of rats gained proportional body weight during the two weeks observation period (Table 1).

Table 1. Mean body weight of rats treated with extract as compared to the controls during the two weeks observation period (expressed as mean $\pm S D E, n=4$ ).

\begin{tabular}{lllll}
\hline Group & Dose $\mathbf{( m g} / \mathbf{k g})$ & Initial mean body weight $\mathbf{( g m )}$ & Mean Body weight at the end of week 1(gm) & Mean Body weight on day 14 (gm) \\
\hline I & 200 & $182.7 \pm 17.9(0.56)$ & $186.34 \pm 18.9(0.56)$ & $198.9 \pm 19.07(0.66)$ \\
II & 700 & $157.8 \pm 6.34(0.54)$ & $160.4 \pm 6.24(0.46)$ & $169.07 \pm 6.98(0.52)$ \\
III & 1200 & $182.42 \pm 5.64(0.9)$ & $187 \pm 5.8(0.99)$ & $204.8 \pm 8.95(0.90)$ \\
IV & 2200 & $173.9 \pm 4.34(0.27)$ & $177.32 \pm 4.65(0.11)$ & $188.55 \pm 5.22(0.07)$ \\
V & 3200 & $194 \pm 4.6(0.39)$ & $198.5 \pm 3.83(0.90)$ & $208.55 \pm 4.62(0.34)$ \\
VI & 4200 & $172 \pm 8.55(0.25)$ & $175.1 \pm 9.17(0.26)$ & $183.67 \pm 9.54(0.23)$ \\
VII & 5000 & $187 \pm 3.18(0.49)$ & $190 \pm 3.22(0.26)$ & $199.22 \pm 4.94(0.18)$ \\
VIII & Control(vehicle) & $169.5 \pm 7.17$ & $177.85 \pm 7.41$ & $188.5 \pm 7.84$ \\
\hline
\end{tabular}

The figures under brackets indicate $\mathrm{p}$-values, $\mathrm{n}$-number of rats per group 


\subsubsection{Effects of Acute Administration of the Extracts on Gross Pathology}

Observation on the gross appearance of internal organs including liver and kidney of treated rats did not show any abnormal changes in texture, shape, size or color in comparison to that of the control. No lesion was noted in these organs in all groups.

\subsection{Subchronic Toxicity Study}

\subsubsection{Effects of Subchronic Administration of the Extracts on Behavior, Gross Pathology and Body Weight}

During the period of 90 days of subchronic toxicity evaluation, repeated oral doses of the extract at $600 \mathrm{mg} / \mathrm{kg}$ body weight showed no change in their general behavior as compared to the control group. Only those which received the higher dose $(1800 \mathrm{mg} / \mathrm{kg})$ showed some signs of toxicity, such as intermittent diarrhea, piloerection and hypoactivity. These signs started on the third day of treatment and continued for three days. There was no abnormal gross finding on skin, eyes as well as on the liver and kidneys in any of the treated groups. Moreover, there was no toxicity related death throughout the study period.

There was a progressive body weight gain in nearly all groups of male and female rats with time over the whole period of the experiment (Fig. $1 \& 2$ ). No significant change was observed in the pattern of body weight gain among the different groups of rats in both experimental groups as well as the controls.

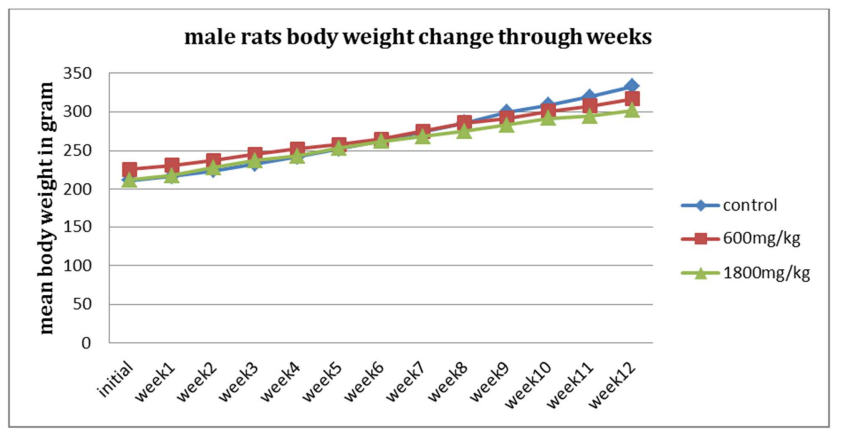

Figure 1. Mean Body weight change in male rats treated with $600 \mathrm{mg} / \mathrm{kg}$ and $1800 \mathrm{mg} / \mathrm{kg}$ extracts as compared to the control.

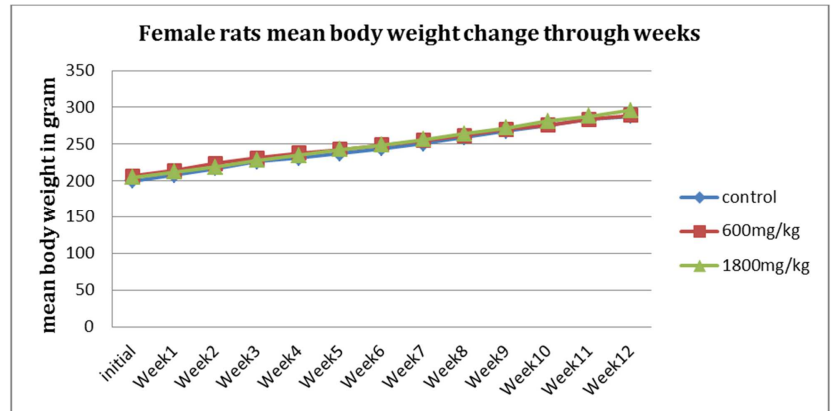

Figure 2. Mean Body weight of female rats treated with $600 \mathrm{mg} / \mathrm{kg}$ and $1800 \mathrm{mg} / \mathrm{kg}$ extract as compared to the controls.

\subsubsection{Effect of Subchronic Oral Administration of Artemisia afra on Gross Morphology of Liver and Kidney of Rats}

Visual gross examination of the liver and kidney of both control and treated rats showed normal architecture, no colour changes and no morphological disturbances. A. afra extract did not produce any significant effect on weight of liver and kidneys at both dose of $600 \mathrm{mg} / \mathrm{kg}$ and $1800 \mathrm{mg} / \mathrm{kg}$ as compared to the control group (Table 2).

Table 2. Mean liver and kidney weight of male and female rats (in gram; mean $\pm S D E$ ) chronically dosed with A. afra as compared to the controls.

\begin{tabular}{lll}
\hline \multirow{2}{*}{ Dose } & \multicolumn{2}{l}{$\begin{array}{l}\text { Mean weight (in gram; mean } \pm \text { SDE; } \mathbf{n}=\mathbf{4} \text { for males } \\
\text { and } \mathbf{n}=\mathbf{5} \text { for females) }\end{array}$} \\
\cline { 2 - 3 } & Liver & \multicolumn{1}{c}{ Kidney(single) } \\
\hline Male & & $1.58 \pm 0.046$ \\
Control & $15.775 \pm 0.69$ & $1.5625 \pm 0.042(0.129)$ \\
$600 \mathrm{mg} / \mathrm{kg}$ & $15.025 \pm 0.557(0.617)$ & $1.56 \pm 0.06(0.939)$ \\
$1800 \mathrm{mg} / \mathrm{kg}$ & $13.92 \pm 0.97(0.962)$ & \\
Female & & $1.5 \pm 0.041$ \\
Control & $14.46 \pm 0.289$ & $1.48 \pm 0.045(0.575)$ \\
$600 \mathrm{mg} / \mathrm{kg}$ & $15.04 \pm 0.435(0.643)$ & $1.494 \pm 0.042(0.561)$ \\
$1800 \mathrm{mg} / \mathrm{kg}$ & $15.18 \pm 0.449(0.944)$ & \\
\hline
\end{tabular}

The figures under brackets indicate $\mathrm{p}$-values, $\mathrm{n}$ - number of rats per group

\subsubsection{Effects of Aqueous Leaf Extract of Artemisia afra on Hematological and Biochemical Parameters}

The aqueous leaf extract of $A$. afra did not produce significant change on any of the hematological parameters tested after its administration for 12 weeks in both male and female rats as compared to the controls (Table 3).

Table 3. Effects of $600 \mathrm{mg} / \mathrm{kg} \& 1800 \mathrm{mg} / \mathrm{kg}$ aqueous leaf extract of A. afra on hematological parameters in male and female rats as compared to the controls. (Expressed as mean $\pm S D E, n=4$ for males and $n=5$ for females).

\begin{tabular}{|c|c|c|c|}
\hline Hematological Parameters & $600 \mathrm{mg} / \mathrm{kg}$ & $1800 \mathrm{mg} / \mathrm{kg}$ & Control (distilled water) \\
\hline \multicolumn{4}{|l|}{ Results of Male rats } \\
\hline $\mathrm{WBC}\left(\mathrm{x} 10^{3} / \mu \mathrm{L}\right)$ & $6.8 \pm 0.35(0.6)$ & $6.9 \pm 0.67(0.4)$ & $6.2 \pm 1.5$ \\
\hline $\mathrm{RBC}\left(\mathrm{x} 10^{6} / \mu \mathrm{L}\right)$ & $8 \pm 0.25(0.16)$ & $8.2 \pm 0.23(1)$ & $7.8 \pm 0.3$ \\
\hline HGB (g/dL) & $15.4 \pm 0.35(0.8)$ & $16.6 \pm 0.37(0.9)$ & $14.5 \pm 0.9$ \\
\hline HCT (\%) & $48.9 \pm 1.4(0.7)$ & $50.9 \pm 2.5(0.64)$ & $50.4 \pm 1.7$ \\
\hline MCV (fL) & $65.2 \pm 0.85(0.74)$ & $63.8 \pm 1.7(0.98)$ & $64.4 \pm 1$ \\
\hline $\mathrm{MCH}(\mathrm{pg})$ & $18.3 \pm 1.19(0.14)$ & $18.9 \pm 1.6(0.35)$ & $18.3 \pm 0.49$ \\
\hline $\mathrm{MCHC}(\mathrm{g} / \mathrm{dL})$ & $26.9 \pm 2.6(0.25)$ & $30.8 \pm 0.96(0.29)$ & $28.5 \pm 1.2$ \\
\hline
\end{tabular}




\begin{tabular}{|c|c|c|c|}
\hline Hematological Parameters & $600 \mathrm{mg} / \mathrm{kg}$ & $1800 \mathrm{mg} / \mathrm{kg}$ & Control (distilled water) \\
\hline $\operatorname{PLT}\left(x 10^{3} / \mu \mathrm{L}\right)$ & $904.3 \pm 9.69(0.12)$ & $881.4 \pm 51.6(0.4)$ & $874.5 \pm 61.23$ \\
\hline NEUT $\left(x 10^{3} / \mu \mathrm{L}\right)$ & $2.3 \pm 0.36(0.46)$ & $2.4 \pm 0.4(0.9)$ & $2.4 \pm 0.27$ \\
\hline Lympho $\left(x 10^{3} / \mu \mathrm{L}\right)$ & $3.8 \pm 0.12(0.46)$ & $3.8 \pm 0.19(0.3)$ & $3.6 \pm 0.15$ \\
\hline Mono $\left(x 10^{3} / \mu \mathrm{L}\right)$ & $0.23 \pm 0.047(0.24)$ & $0.19 \pm 0.04(0.78)$ & $0.23 \pm 0.04$ \\
\hline \multicolumn{4}{|l|}{ Results of Female rats } \\
\hline $\mathrm{WBC}\left(\mathrm{x} 10^{3} / \mu \mathrm{L}\right)$ & $5.97 \pm 0.98(0.34)$ & $6.9 \pm 1.9(0.35)$ & $5.4 \pm 0.44$ \\
\hline $\mathrm{RBC}\left(\mathrm{x} 10^{6} / \mu \mathrm{L}\right)$ & $6.9 \pm 0.35(1)$ & $7 \pm 0.3(0.84)$ & $7.1 \pm 0.42$ \\
\hline HGB (g/dL) & $14.8 \pm 0.8(0.77)$ & $14.9 \pm 0.9(0.86)$ & $15.3 \pm 1.0066$ \\
\hline HCT (\%) & $48.7 \pm 0.8(0.34)$ & $46 \pm 2.3(0.74)$ & $46.9 \pm 3.6$ \\
\hline MCV (fL) & $66.27 \pm 1.3(0.59)$ & $65.4 \pm 0.78(0.96)$ & $66.3 \pm 1.23$ \\
\hline $\mathrm{MCH}(\mathrm{pg})$ & $21.57 \pm 0.09(0.64)$ & $21 \pm 0.44(0.25)$ & $21.6 \pm 0.29$ \\
\hline $\mathrm{MCHC}(\mathrm{g} / \mathrm{dL})$ & $32.1 \pm 0.12(1)$ & $32.4 \pm 0.4(0.84)$ & $32.6 \pm 0.4$ \\
\hline $\operatorname{PLT}\left(\mathrm{x} 10^{3} / \mu \mathrm{L}\right)$ & $778 \pm 45.08(0.77)$ & $806 \pm 9.24(1)$ & $832 \pm 39.2$ \\
\hline NEUT $\left(x 10^{3} / \mu \mathrm{L}\right)$ & $2.23 \pm 0.24(0.46)$ & $2.04 \pm 0.089(0.64)$ & $2.3 \pm 0.4$ \\
\hline Lympho $\left(x 10^{3} / \mu \mathrm{L}\right)$ & $3.3 \pm 0.35(0.16)$ & $3.77 \pm 0.17(0.64)$ & $3.3 \pm 0.24$ \\
\hline Mono $\left(x 10^{3} / \mu \mathrm{L}\right)$ & $0.18 \pm 0.018(0.64)$ & $0.17 \pm 0.04(1)$ & $0.15 \pm 0.035$ \\
\hline
\end{tabular}

The figures in brackets indicate the calculated $\mathrm{p}$ values of the treatment groups as compared to the control and $\mathrm{n}=$ no of rats per group.

Table 4. Effect of $600 \& 1800 \mathrm{mg} / \mathrm{kg}$ aqueous leaf extract of A. afra on biochemical parameters in male rats as compared to the control group (expressed in mean $\pm S D E, n=4$ for males and $n=5$ for females).

\begin{tabular}{|c|c|c|c|}
\hline Parameters & Control & $600 \mathrm{mg} / \mathrm{kg}$ & $1800 \mathrm{mg} / \mathrm{kg}$ \\
\hline \multicolumn{4}{|l|}{ Male } \\
\hline AST(IU/L) & $199.75 \pm 30.8$ & $198 \pm 1.45(0.78)$ & $194 \pm 13.7(0.16)$ \\
\hline ALT (IU/L & $175.25 \pm 26.1$ & $177.3 \pm 2.07(0.84)$ & $181 \pm 34.9(0.17)$ \\
\hline Total Bilirubin & $0.5525 \pm 0.09$ & $0.53 \pm 0.08(0.747)$ & $0.8 \pm 0.13(0.321)$ \\
\hline Urea $(\mathrm{mg} / \mathrm{dL})$ & $47.75 \pm 5.4$ & $48 \pm 7(0.843)$ & $53 \pm 3.2(0.70)$ \\
\hline Creatinine $(\mathrm{mg} / \mathrm{dL})$ & $0.9825 \pm 0.08$ & $1.04 \pm 0.02(0.46)$ & $1.01 \pm 0.13(0.55)$ \\
\hline \multicolumn{4}{|l|}{ Female } \\
\hline AST(IU/L) & $178 \pm 37.75$ & $171.6 \pm 29.3(0.495)$ & $131.3 \pm 16.169(0.034) * *$ \\
\hline ALT (IU/L) & $135.3 \pm 19.9$ & $134 \pm 6.5(0.835)$ & $119.6 \pm 24.3(0.385)$ \\
\hline Total Bilirubin & $0.8 \pm 0.13$ & $0.76 \pm 0.109(0.051)$ & $0.68 \pm 0.06(0.948)$ \\
\hline Urea (mg/dL) & $51 \pm 5.196$ & $54.3 \pm 10.7(0.851)$ & $36 \pm 2.517(0.22)$ \\
\hline Creatinine $(\mathrm{mg} / \mathrm{dL})$ & $1.0167 \pm 0.105$ & $1.14 \pm 0.17(0.613)$ & $0.76 \pm 0.026(0.878)$ \\
\hline
\end{tabular}

The figures under brackets indicate $\mathrm{p}$-values, **: significant, $\mathrm{n}$ - number of rats per group

Similarly there was no significant change in ALT, bilirubin, creatinine and urea levels in both male and female groups that received $A$. afraat doses of $600 \mathrm{mg} / \mathrm{kg}$ and $1800 \mathrm{mg} / \mathrm{kg}$ compared with the control (Table 4). AST levels were not changed in the male groups at both doses and the female rats at $600 \mathrm{mg} / \mathrm{kg}$ dose though there was significant $(\mathrm{P}<0.05)$ decrement in the female rats at $1800 \mathrm{mg} / \mathrm{kg}$.

\subsubsection{Effects of Subchronic Administration of the Extract on Histology of the Liver}

Microscopic examination of liver sections of the control rats (Figure 3A \& 3B) showed the normal architecture of structural units of the liver, the hepatic lobules, formed by cords of hepatocytes separated by hepatic sinusoids. Additionally, the central vein and portal area containing branches of hepatic artery, billary duct and portal vein revealed normal appearance. In comparison to the control, the general microscopic architecture of the liver tissue sections of both male and female rats treated with $600 \mathrm{mg} / \mathrm{kg}$ body weight dose (Figure 3C \& 3D) of the extracts obtained from $A$. afra appeared to be not significantly affected after 90 days administration.

However, liver sections of male and female rats treated with $600 \mathrm{mg} / \mathrm{kg}$ body weight showed minor periportal mononuclear leukocytic infiltration (Figure 3D). In addition in the sections of male and female rats treated with $1800 \mathrm{mg} / \mathrm{kg}$ body weight 
(Figure 3E \& 3F), the liver appeared normal. However, minor inflammatory changes near the central veins and portal area occurred as evidenced by the presence of mononuclear leukocytic cell infiltration. The histology of liver from male and female rats was similar, and there was no difference in the liver sections of male and female treated rats for each of the two doses as well as the controls.
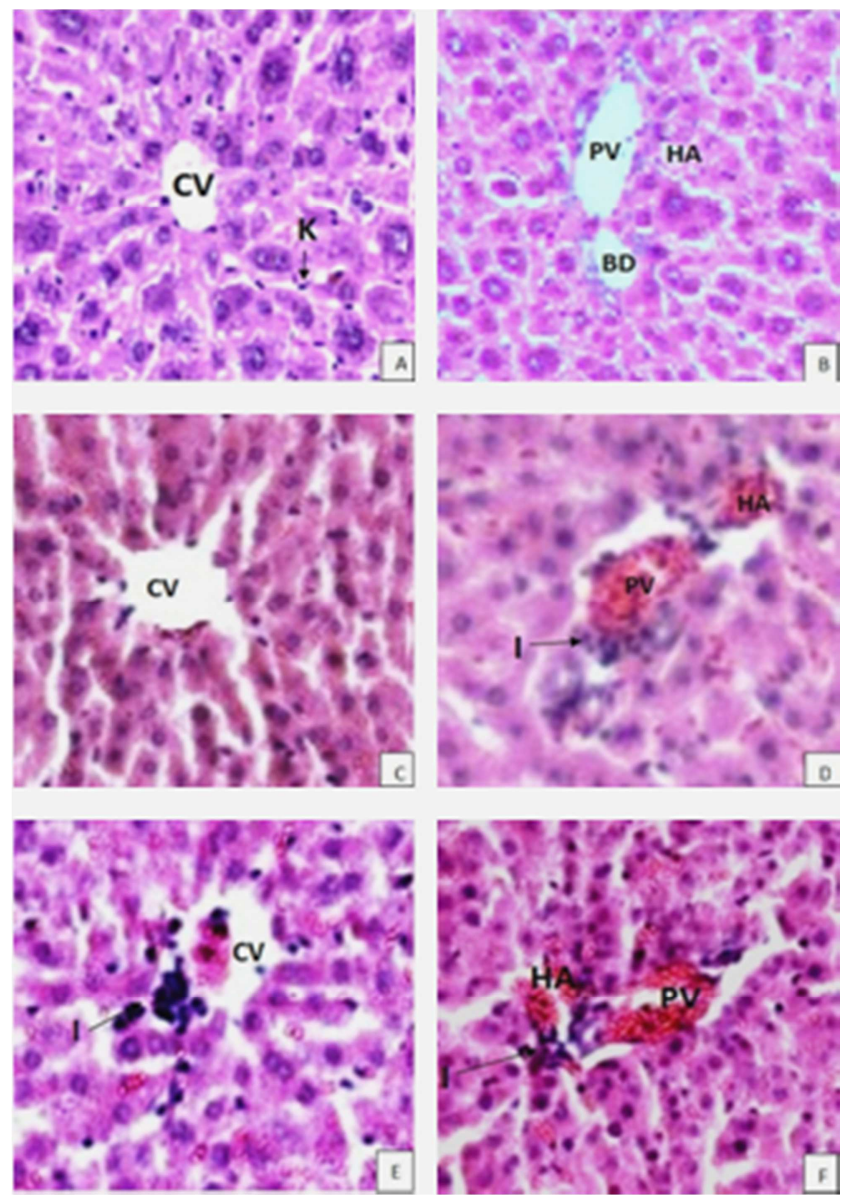

Figure 3. Photomicrographs of liver sections of control rats $(A \& B)$, and rats treated with A. afra leaves extract at $600 \mathrm{mg} / \mathrm{kg}$ body weight (C\&D), and $1800 \mathrm{mg} / \mathrm{kg}$ body weight $(E \& F)$. Sections are from female rats. $C V=$ Central vein, $E=$ Endothelial cells, $P V=$ Portal vein, $B D=$ Bile duct, $H A=$ Hepatic artery, $K=$ Kupffer cells, I= leukocytic Infiltration. (Sections were stained with $H \& E, X 400)$. Note: leukocytic Infiltration (I) the liver sections of rats treated with the extract at dose $600 \mathrm{mg} / \mathrm{kg}(D)$ and $1800 \mathrm{mg} / \mathrm{kg}(E)$ and $(F)$.

\subsubsection{Effects of Subchronic Administration of the Extract on Histology of the Kidneys}

Examination of kidney sections of both male and female rats treated with the extract of $A$. afra at both $600 \mathrm{mg} / \mathrm{kg}$ (Figure 4C \& 4D) and $1800 \mathrm{mg} / \mathrm{kg}$ (Figure 4E \& 4F) indicated no structural change as compared to the control rats (Figure 4A \& 4B). The microscopic architecture of the kidneys in treated male and female rats had similar appearance to that of the controls in which renal corpuscles maintaining their normal size of urinary space and normal tubular structures were observed. However, minor tubulointerstitial leukocytic infiltration was observed in small areas of kidney sections of both male and female rats treated with $1800 \mathrm{mg} / \mathrm{kg}$ body weight (Figure 4F)
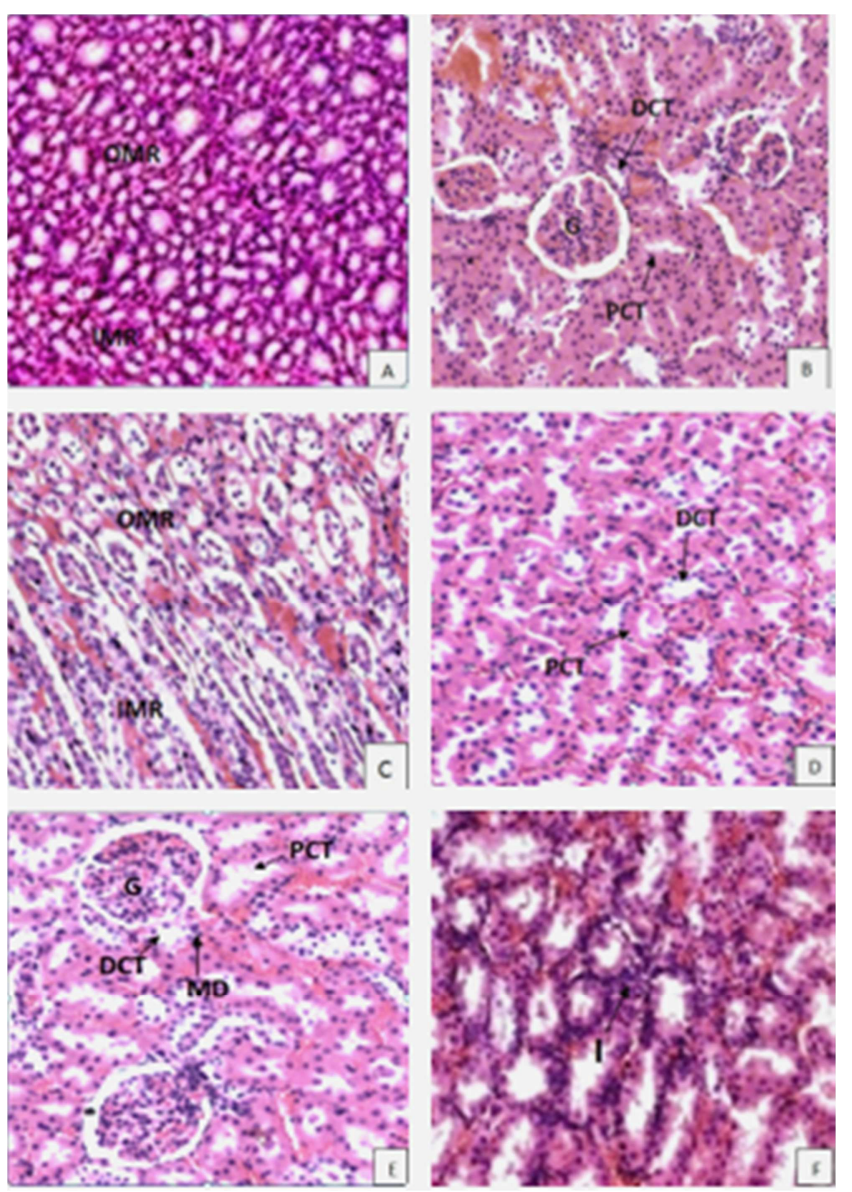

Figure 4. Photomicrographs of kidney sections of control rats $(A \& B)$, and rats treated with $A$. afra leaves extract at $600 \mathrm{mg} / \mathrm{kg}$ body weight $(C \& D)$, and $1800 \mathrm{mg} / \mathrm{kg}$ body weight $(E \& F)$. Sections are from female rats. $G=$ Glomerulus, $D C T=$ Distal convoluted tubule, $P C T=$ proximal convoluted tubule, $I=$ leukocytic Infiltration, $M D=$ Macula densa, OMR $=$ outer medullary region, IMR $=$ inner medullary region. (Sections were stained with $H \& E, X 300)$. Note: Tubulointerstitial leukocytic infiltration with the extract at dose of $1800 \mathrm{mg} / \mathrm{kg}(F)$.

\section{Discussions}

An acute toxicity test is conducted in a suitable animal species with a single dose and may be done for essentially all chemicals that are of any biologic interest. Its purpose is to see the signs of toxicity and determine the order of lethality of the compound $[24,25]$. In the present study, the aqueous extract of $A$. afra did not show any mortality with single oral dose up to $5000 \mathrm{mg} / \mathrm{kg}$ body weight. The present result, therefore, suggests that the oral $\mathrm{LD}_{50}$ of the extract is greater than $5000 \mathrm{mg} / \mathrm{kg}$. Besides, behavioral changes such as loss of appetite, hypo-activity, pilo-erection, lethargic, dizziness and convulsion started to appear at the dose of $3200 \mathrm{mg} / \mathrm{kg}$. The symptoms, however, disappeared after the $1^{\text {st }}$ week of observation. The present result is in agreement with the previous study which did not produce lethality up to $8460 \mathrm{mg} / \mathrm{kg}$ following oral administration of Artemisia afra indicating that the extract is relatively non-toxic [26].

In the 14 days acute toxicity study, the weight gain of rats treated with doses up to $5000 \mathrm{mg} / \mathrm{kg}$ was not significantly different from that of the control group. Furthermore, no 
gross pathological changes such as in color, organ swelling, texture and atrophy or hypertrophy were observed after single administration of the extract as compared with the control group. Therefore, the overall weight gain in both treated and control rats and the absence of gross pathological changes indicate the good health status of the animals. In all groups these results of the acute toxicity study go in-line with other previous study by Mukinda and Syce [27] in which the body weights and gross anatomy of some of the internal organs including liver and kidney of rat and mice treated with acute and chronic oral administration of $A$. afra also not significantly changed as compared to the control.

There was no significant deviation in the behavior of the rats treated with the low dose $(600 \mathrm{mg} / \mathrm{kg})$ as compared to that of the control group, and essentially all the treated rats remained healthy during the 3-month period of chronic oral administration of $A$. afra, only rats in the group which received the higher dose $(1800 \mathrm{mg} / \mathrm{kg})$ manifested minor signs of toxicity. Significant changes in body-weight have been used as an indicator of adverse effects of drugs and chemicals [28]. In the present study, there was no significant change in weight of both male and female rats throughout the study period, although there was a progressive non significant weight increment in both treated and the control groups. Increment in body weight determines the positive health status of the animals [29]. Therefore, the overall weight gain in both treated and control rats might indicate a good health status of the experimental animals. According to $\mathrm{Lu}$ [30], a remarkable change in relative organ weights between treated and untreated animals is an indicator of toxicity as organ weight is affected by the suppression of body weight. However, in the present study there was no significant change in organ (liver and kidney) weights and visual gross examination of the organs of both treated rats and the controls. These showed normal architecture, no colour change and no morphological disturbances, indicating that the subchronic oral doses of $A$. afra extract administered had no effect on the organs of the rats and was well tolerated over the 3-month study period.

Hematological parameters were evaluated to obtain further toxicity related information, not detected by direct examination of organs and body weight analysis. While the hematopoietic system is one of the most sensitive targets for toxic compounds [31], there were no significant differences in the white blood cell with its differential, red blood cell haematocrits, mean corpuscular volume, mean corpuscular hemoglobin concentration and platelet counts of the treated versus the control rats. These results indicate that 3-month administration of $A$. afra had no effect on the circulating cells nor interfered with their production.

Liver and renal function tests have a significant importance to evaluate changes produced by a toxicant. This is because of their response to clinical signs and symptoms. To assess the possible toxic effect of a drug, evaluation of hepatic and renal function is primarily preferred as these organs are functionally predisposed. Elevated serum levels of enzymes produced by the liver or nitrogenous wastes to be excreted by the kidney might be an indication to their spillage into the blood stream as a result of necrosis of the tissues [32]. It was thus important to investigate the effect of A. afra on the function of these organs.

Because of its wide range of functions, any abnormal change in liver will definitely affect complete metabolism [33]. The major intracellular enzymes of the liver which are alanine amino transferase (ALT) and aspartate amino transferase (AST) are useful enzymes as biomarkers predicting possible toxicity [32]. The level of AST obtained in this study, showed a dose dependent significant decrement in the female treated group at the dose of $1800 \mathrm{mg} / \mathrm{kg}$. In line with this, a previous study [26] had shown significant decrement of the AST levels at higher dose treatment group at day 92 suggesting that at higher doses, A. afra does not adversely affect the cell mitochondria. Also oral administration of aqueous extract of $A$. afra attenuated the elevated activities of all investigated liver enzymes including AST in diabetic rats [21]. This may be an indication of nontoxic nature and protective action of the extract in reversing liver damage due to diabetes. In the present study there was no significant change of ALT in both male and female treated groups at doses of $600 \mathrm{mg} / \mathrm{kg}$ and $1800 \mathrm{mg} / \mathrm{kg}$. These suggest that $A$. afra does not adversely affect the hepatocytes; in fact it may even stabilize the organelles (brought level back to the day 0 levels).

An elevation in direct bilirubin is highly specific for billary tract obstruction. However, impaired billary excretion, which is an energy-dependent process, is thought to be the reason for increased levels observed in sepsis, total parenteral nutrition, and following surgery [34]. Due to its small molecular size and water-soluble properties, direct bilirubin appears in urine [35]. In this study there was no significant change of bilirubin on both treated groups of male and female rats. This indicates that the plant Artemisia afra does not have a role in derangement of liver functions.

Urea \& creatinine are the parameters widely used to diagnose functioning of the kidneys. Changes in serum creatinine concentration more reliably reflect changes in Glomerular filtration rate (GFR) than do changes in serum urea concentrations. Creatinine is formed spontaneously at a constant rate, and blood concentrations depend almost solely upon GFR. Urea formation is influenced by a number of factors such as liver function, protein intake and rate of protein catabolism [36]. The rise in serum level of these chemicals indicates a decline or failure in renal function to filter waste products from the blood and excrete them in the urine [37].

In the present study the subchronic oral administration of the extract did not show significant alteration in the serum levels of urea and creatinine concentrations in rats treated with both doses as compared to the controls. Thus, absence of change in the levels of the above renal function markers suggests that the extract does not cause deterioration in the renal function. This is in accordance with Mukinda and Syce[27] who investigated the safety of $A$. afra aqueous extract (mimicking the traditional decoction dosage form) by 
determining its pharmaco-toxicological effects after acute and chronic administration to rats and mice, respectively.

Histopathological examinations provide information to strengthen the findings on biochemical and hematological parameters. Cell death due to toxicity occurs via necrosis, in which isolated hepatocytes become shrunken, pyknotic, and intensely eosinophilic [38]. Pyknosis causes the formation of dark staining masses against the nuclear membrane [39]. In addition, damage from toxic or immunologic insult may cause hepatocytes to take on a swollen, edematous appearance (ballooning degeneration) with irregularly clumped cytoplasm and large, clear spaces [38]. Such hepatocytes damage did not occur in the present study as there was no focal necrosis, Pyknosis, enlarged or fragmented nucleus within cytoplasm of hepatocytes at both 600 and $1800 \mathrm{mg} / \mathrm{kg}$ doses.

On the other hand, there were minor periportal leukocytic infiltration at dose $600 \mathrm{mg} / \mathrm{kg}$ and mild mononuclear leukocytic cell infiltration near central vein and portal area at the dose of $1800 \mathrm{mg} / \mathrm{kg}$. However, such minor inflammatory changes obtained in this study were not accompanied by significant change in any of the hematological and biochemical markers of liver injury measured. The reason for the occurrence of the leukocytic infiltration is not clear, but it might be a response to parenchymal cell death with causes ranging from exposure to toxicants, generation of toxic metabolites, and tissue anoxia.

In agreement with the present findings a study conducted by Mukinda and Syce [27] had shown no significant change in haematological and biochemical parameters, except for transient decrease in AST level. Moreover, there were no effect on the levels of AST and ALT, which are considered to be sensitive indicators of hepatocellular damage and within limits can provide a quantitative evaluation of the degree of damage to the liver [40]. It is reasonable to deduce, therefore, that $A$. afra does not induce a significant damage to the liver at both doses of the present study in rats.

In line with the biochemical findings (the amount of creatinine and urea), the general histological architecture were not affected in any of the treatment groups as compared to the control, although minor tubulointerstitial lymphocytic infiltration were observed in some kidney sections of rats treated with the extraction only at $1800 \mathrm{mg} / \mathrm{kg}$ body weight dose. Related study [27] had also concluded that acute and chronic oral administration of aqueous extract of $A$. afra was not toxic to the kidney in rat and mice, respectively.

\section{Conclusion}

In conclusion, findings from the acute toxicity test suggest that A. afra leaf aqueous extract is non-toxic when administered orally. Further studies, however, are required to assure the safety the extract on other organs like gastro intestinal tract, parts of brain and cardiovascular system, and other animals are needed to be investigated.

\section{Authors' Contributions}

MA advisor from proposal development to the end of the study. He genuinely guided the histopathological part of the study and the research work to the conclusion as well as preparation of the manuscript. $\mathrm{AD}$ continues advice and provision of materials which were pertinent for this research work, EM contributes from dose selection and dosing up to proofreading of this research work, WE interpretation of the pathological findings and TT provided the research topic and animal laboratories.

\section{Conflict of Interests}

The authors declare that they have no competing interests and they all revised the paper and the manuscript of their respective portion or discipline.

\section{Acknowledgements}

We greatly thank the school of graduate studies, AAU and Ethiopian Public Health Institution for their partial support of the study.

\section{References}

[1] Ahmedulla, M. and M. P. Nayer, Red data book of Indian plants. Calcutta: Botanical survey of India, 1999. Vol. 4: p. 14-17.

[2] Tabuti, J. R. S., K. A. Lye, and S. S. Dhillion, Traditional herbal drugs of Bulamogi, Uganda: plants use and administration. J. Ethno-pharmacology, 200388: p. 19-44.

[3] Lewington, Medicinal plants and plant extracts:A Review of their Importation into Europe. Cambridge, UK.1993: p. 92.

[4] Fennell, C. W., et al., Assessing African medicinal plants for efficacy and safety: pharmacological screening and Toxicology. Journal of Ethnopharmacology, 2004. 94(2-3): p. 205-217.

[5] Miruts, G., et al., An ethnobotanical study of medicinal plants used by the Zay people in Ethiopia. J. Ethnopharmacol., 2003. 85(1): p. 43-52.

[6] Pappas, R. and S. Sheppard- Hanger, Artemisia arborescensessential oil of the Pacific Northwest: a high-chamazulene, low-thujone essential oil with potential skin- care applications. Atlantic institute, Reference manual www.atlanticinstitute.com/artemisia.pdf 2004.

[7] Abebe, D. Traditional Medicinein Ethiopia:Theattemptsbeing madetopromoteitforeffectiveandbetterutilization. SINET: Ethiopian J., 1986. Sci. 9: p. 61-69.

[8] Mucciarelli, M. and M. Maffei, Introduction to the genus Artemisia. In Wright CW (ed) Medicinal and Aromatic Plants - Industrial Profiles, Taylor \& Francis, London, 2002(ISBN:04152721212): p. 1-50.

[9] Mander, M., Marketing of Indigenous Medicinal Plants in South Africa: A Case Study in KwaZulu-Natal. Food and Agricultural Organization of the United Nations, Rome.1998. 
[10] Cunningham, A., et al., Zulu Medicinal Plants: An inventory. South Africa, University of Natal press. Scottsville, 1996: p. 327.

[11] Dyson, A., Discovering indigenous healing plants of the herb and fragrance gardens at Kirstenbosch National Botanical Garden. Cape Town. National Botanical Institute, the Printing Press, 1998: p. 9-10.

[12] Iwu M., Hand book of African Medicina lplants. USA, Florida, CRC Press, 1993: p. 121-122.

[13] Roberts, M., Indigenous healing plants. South Africa. Southern Book, 1990: p. 226-228.

[14] Harris, L., An evaluation of the bronchodilator properties of Mentha Longifolia and Artemisia afra, traditional medicinal plants used in the Western Cape M. Thesis, Discipline of pharmacology. School of pharmacy, University of the Western Cape. Bellville. 2002.

[15] MRC and S. Healthinfo, Traditional medicines database: www.mrc.ac.za/Tramed3/Tramed3PlantPharmacologyDetails. 2004.

[16] Moges, K., et al., In Vitro Test of Five Ethiopian Medicenal Plants for Antimalarial activity againest plasmodium Falciparum. Ethiop. J. Sci 1998. 21(1): p. 81-89.

[17] Gericke, N., O. B. Van, and B.-E. Van Wyk, Medicinal plants of South Africa.2nd ed. Tien Wah Press, Singapore:, 2000. 44.

[18] Debella, A., Manual for phytochemical screening of medicinal plants. Department of DrugResearch, EHNRI, Addis Ababa, Ethiopia. 2002: p. 1-55.

[19] Vipul, G., et al., Hepathoprotective activity of alcoholic and aqueous extracts of leaves of Tylophora indica (Linn.) in rats. Indian J. Pharmacol, 2007. 39: p. 43-47.

[20] WHO, General Guidelines for Methodologies on Research and Evaluation of Traditional Medicine. WHO/EDM/TRM/2000.1.

[21] Taofik, S. and A. Anthony, Evaluation of Antidiabetic Activity and Associated Toxicity of Artemisia afra Aqueous Extract in Wistar Rats African J. of Complementary and Alternative Medicine 2013. 1(8).

[22] OECD, Guidelines for testing of chemicals acute oral toxicicty - Fixed Dose Procedure. 2008: p. 1-12.

[23] OECD, Guidelines for testing of chemicals acute oral toxicicty - Fixed Dose Procedure 2008: p. 1-12.

[24] Loomis, T. A. and A. W. Hayes, Loomis's essentials of toxicology. 4th ed., California, Academic press. 1996: p. 208245.
[25] Pascoe, D., Toxicology. England, London, Edward Arnold limited. 1983: p. 1-60.

[26] James, T., Acute and chronic toxicity of the flavonoidcontaining plant, Artemisia afra in rodents 2005: p. 66-74.

[27] Mukinda, J. and J. Syce, Acute and chronic toxicity of the aqueous extract of Artemisia afra in rodents. $J$ Ethnopharmacol 2007. 112: p. 138-144.

[28] Hilaly, J. E., Z. H. Israili, and B. Lyoussi, Acute and chronic toxicological studies of Ajuga Ivain experimental animals. J. Ethno-pharmacology,, 2004. 91: p. 43-50.

[29] Heywood, Long term toxicity. In: Balls M, Riddell RJ, and Worden AN, editors, Animals and alternatives in toxicity testing, London: Academic Press. 1983: p. 79-89.

[30] Lu, F., Basic Toxicology: fundamentals, target organs and risk assessment, 3rd edition, Taylor and Francis, Washington. 1996: p. 17-86.

[31] Harper, H. A., Review of physiological chemistry, 14th ed. California, Lange medical publications. 1993: p. 185-402.

[32] Rahman, M. F., M. K. Siddiqui, and K. Jamil, Effects of Vepacide (Azadirachta indica) on aspartate and alanine aminotransferase profiles in a sub chronic study with rats. J. Human and Experimental Toxicology, 2001. 20: p. 243-249.

[33] Paliwal, A., R. Gurjar, and H. Sharma, Analysis of liver enzymes in albino rat under stress of $\lambda$-cyhalothrin and nuvan toxicity. Biol. and Medic, 2009. 1(2): p. 70-73.

[34] Zimmerman, H., Intrahepatic cholestasis. Arch Intern Med, 1979. 139: p. 1038-45.

[35] Thapa, B. and A. Walia, Liver function test and their interpretation. Indian J. Pediatrics, 2007. 74: p. 67-75.

[36] Griffin, K., H. Kramer, and A. Bidani, Adverse renal consequences of obesity. American Journal of Physiology RenalPhysiology, 2008. 294: p. 685-696.

[37] Paula, A. and A. Mark, Kidney function test. Retrieved on 5 April 2013 fromwww.surgeryencyclopedia.com. 2011.

[38] Kumar, V., R. Cotran, and S. Robbins, Robbins Basic Pathology7th ed. Elsevier Saunders, Philadelphia, 2002: p. 592-593.

[39] Young, A., The physiology of lymphocyte migration through the single lymph node in vivo. Seminars in Immunol., 2006. 11: p. 73-83.

[40] Thierry, et al., Sub acute toxicity study of the aqueous extract from Acanthus montanus Djami Tchatchou. Electronic J. Biol. 2011: p. 7(1): 11-15. 